\title{
Prinzmetal Variant Angina Associated with Multiple Sclerosis
}

Scott Joing, MD, Robyn Casey, MD, and Les Forgosh, MD

We report the case of a young woman with an acute coronary syndrome in the setting of a multiple sclerosis exacerbation. A connection between the 2 , possibly caused by spinal cord pathology, is suggested. (J Am Board Fam Pract 2004;17:71-3.)

Prinzmetal variant angina is characterized by angina secondary to coronary artery vasospasm, ${ }^{1}$ typically at rest, associated with transient ST-segment deviations. ${ }^{2}$ Further diagnostic workup using angiography may reveal coronary arteries with or without atherosclerotic narrowings. ${ }^{1}$ Multiple sclerosis (MS) is typically a relapsing-remitting neurologic disorder involving demyelinated plaques, which slow or block conduction along nerves. ${ }^{3}$ Literature search reveals one case report indicating a causal relationship between these 2 diseases. ${ }^{4} \mathrm{We}$ present an additional case involving a 38-year-old patient who experienced Prinzmetal variant angina during a multiple sclerosis relapse.

\section{Case Report}

A 38 year-old hospitalized woman was receiving an intravenous injection of meperidine for abdominal pain when she complained of severe chest pain and pressure that radiated to her neck, jaw, and left arm. She had mild shortness of breath and diaphoresis.

The patient had been admitted 2 days earlier with nausea, vomiting, and abdominal pain after starting an oral prednisone taper for a recent MS exacerbation. Magnetic resonance imaging (MRI) on admission showed multiple foci of increased $\mathrm{T}_{2}$ signal intensity, in the periventricular subcortical distribution, consistent with MS. Two new foci were seen in the right hemisphere, one in the centrum semiovale and another in the right inferior parietal lobe, just above the calcarine fissure. These demonstrated increased signal on the diffusion im-

Submitted 1 April 2003.

From the Hennepin County Medical Center (SJ); Department of Family Practice, University of Minnesota School of Medicine (RC, LF); and Saint Paul Cardiology (LF), Saint Paul. Address correspondence to Les Forgosh, Saint Paul Cardiology, 17 West Exchange Street \#750, Saint Paul, MN 55102 (e-mail: lforgosh@mamn.com). ages, suggesting a more acute process of demyelination. The patient denied any previous episodes of chest pain as well as any cardiac history, hypertension, hypercholesterolemia, or respiratory problems. Past medical history included MS, depression, possible seizure disorder, tonsillectomy, and appendectomy. She was adopted, and her family history is unknown. Her usual medications include $150 \mathrm{mg}$ of ranitidine twice daily, $50 \mathrm{mg}$ of sertraline twice daily, $100 \mathrm{mg}$ of amantadine twice daily, 100 $\mathrm{mg}$ of carbamazepine twice daily, norethindrone and ethinyl estradiol, propoxyphene napsylate as needed, and interferon $\beta 1$ a once per week. She was married with 2 children and she had smoked $<1$ pack of cigarettes per week for the prior 20 years. She rarely used alcohol, and she denied any drug use or herbal medications. Ten days before admission, she had lost her father to a stroke; his funeral was 3 days before admission.

When examined, her temperature was $97.4^{\circ} \mathrm{F}$, pulse was 50 to 70 beats $/ \mathrm{min}$, blood pressure was $130 / 70 \mathrm{~mm} \mathrm{Hg}$, respiratory rate was 20 breaths/ min with an oxygen saturation of $99 \%$ on 2 liters of $\mathrm{O}_{2}$ via nasal cannula. In general, she was a pleasant, healthy woman who appeared moderately uncomfortable and anxious. Results of the examination were unremarkable.

Her electrocardiogram showed 1-mm ST segment elevation in leads II, III, and aVF, suggesting an acute inferior myocardial infarction. Her chest radiograph was negative for acute processes. After administration of oxygen, aspirin, $0.4 \mathrm{mg}$ of sublingual nitroglycerin, heparin, and intravenous morphine, her pain decreased. Her initial cardiac enzymes were elevated: creatine kinase, $98 \mathrm{IU} / \mathrm{L}$; creatine kinase $\mathrm{MB}$ fraction, $12 \mathrm{ng} / \mathrm{mL}$; MB index, $12.2 \%$; and troponin, $7.2 \mathrm{ng} / \mathrm{mL}$. Forty minutes after her initial electrocardiogram, the ST segment elevations were resolving. Cardiac enzymes were 
elevated 2.5 hours later: creatine kinase, 197 IU/L; creatine kinase $\mathrm{MB}, 27 \mathrm{ng} / \mathrm{mL}$; $\mathrm{MB}$ index, $13.7 \%$; and troponin, $20.1 \mathrm{ng} / \mathrm{mL}$.

The next day, the patient was taken for a diagnostic left ventricular catheterization. Findings included $10 \%$ stenosis in both proximal portions of the left anterior descending artery and circumflex artery. The right coronary artery revealed a $70 \%$ stenosis in the proximal portion, which was believed to represent coronary spasm. This stenosis resolved after the administration of intracoronary nitroglycerin via catheter. Echocardiogram suggested inferior hypokinesis. The patient's MS symptoms resolved after starting intravenous methylprednisolone. She was discharged from the hospital 2 days later on a $\beta$-adrenergic receptor blocker, a calcium channel blocker, and coated aspirin in addition to her usual medications. She was believed to have an acute coronary syndrome from coronary spasm.

\section{Discussion}

A search of the literature reveals a single case report describing a 53-year-old woman diagnosed with multiple sclerosis during a hospital admission for severe angina at rest that was consistent with Prinzmetal angina. ${ }^{4}$ In their patient, Lalouschek et $\mathrm{al}^{4}$ found ST-segment depression in leads V2 through $\mathrm{V} 6$, resolution of pain and electrocardiographic abnormalities with administration of intravenous nitroglycerin, and normal coronary arteries on coronary angiography. Evaluation of lower extremity paresthesias led Lalouschek et $\mathrm{al}^{4}$ to a diagnosis of multiple sclerosis; multiple white matter lesions of the head and thoracic spinal cord were evident on MRI. Because sympathetic preganglionic nerve fibers serving the heart originate in the thoracic spinal cord, Lalouschek et $\mathrm{al}^{4}$ implicated the spinal cord lesion found in their patient as the cause of coronary vasoconstriction. Our 38-year-old patient's multiple sclerosis relapse may have contributed to coronary vasospasm in a similar fashion. Although her spinal cord was not imaged, head MRI revealed multiple white matter lesions; at least 2 lesions were acute.

The exact mechanisms responsible for coronary artery vasospasm have not been determined, and causes may vary from patient to patient. Willerson et $\mathrm{al}^{5}$ considered the possibilities of changes in autonomic neural control, changes in contractile function, and locally released vasoactive mediators in contact with dysfunctional endothelium. Additional potential contributing factors to our patient's coronary vasospasm include her history of cigarette smoking, ${ }^{6-8}$ mental stress, ${ }^{9}$ and oral contraceptive use. ${ }^{10}$

Although patients with multiple sclerosis have been shown to be at risk for various forms of cardiovascular dysfunction, ${ }^{11}$ Prinzmetal variant angina has not been evaluated in this population. The cases of our patient and that of Lalouschek et $\mathrm{al}^{4}$ may indicate an association between multiple sclerosis and Prinzmetal variant angina. In general, the prevalence of multiple sclerosis in North America is 50 per $100,000 .{ }^{12}$ Given the unknown prevalence of Prinzmetal angina, ${ }^{13}$ statistical data on the odds of coincidental occurrence of these 2 diseases in a single patient are impossible to calculate. Further studies would be helpful to clarify whether or not there is a relationship between these 2 diseases and might lead to prevention of chest pain and other forms of cardiovascular morbidity through prophylactic treatment of patients at risk. If such a connection were found, MRI of the spinal cord might locate MS lesions associated with coronary spasm.

\section{References}

1. Maseri A, Pesola A, Marzilli M, et al. Coronary vasospasm in angina pectoris. Lancet 1977;1:713-7.

2. Prinzmetal M, Kennamer R, Merliss R, Wada W, Bor N. Angina pectoris. I. A variant form of angina pectoris. Am J Med 1959;27:375-88.

3. Noseworthy J, Lucchinetti C, Rodriguez M, Weinshenker B. Multiple sclerosis. N Engl J Med 2000; 343:938-52.

4. Lalouschek W, Muller C, Gamper G, Weissel M, Turetschek K. Myocardial ischemia with normal coronary arteries associated with thoracic myelitis [letter]. N Engl J Med 1997;337:1920.

5. Willerson J, Hillis D, Winniford M, Maximilian B. Speculation regarding mechanisms responsible for acute ischemic heart disease syndromes. J Am Coll Cardiol 1986;8:245-50.

6. Nobuyoshi M, Abe M, Nosaka H, et al. Statistical analysis of clinical risk factors for coronary artery spasm: identification of the most important determinant. Am Heart J 1992;124:32-8.

7. Caralis D, Deligonul U, Kern M, Cohen J. Smoking is a risk factor for coronary spasm in young women. Circulation 1992;85:905-9.

8. Sugiishi M, Takatsu F. Cigarette smoking is a major risk factor for coronary spasm. Circulation 1993;87: 76-9.

9. Yoshida K, Utsunomiya T, Morooka T, et al. Mental 
stress is an effective inducer of vasospastic angina pectoris: comparison with cold pressor, hyperventilation and master two-step exercise test. Int J Cardiol 1999;70:155-63.

10. Jugdutt B, Stevens G, Zacks D, Lee S, Taylor R. Myocardial infarction, oral contraception, cigarette smoking, and coronary artery spasm in young women. Am Heart J 1983;106:757-61.
11. Acevedo A, Nava C, Arriada N, Violante A, Corona T. Cardiovascular dysfunction in multiple sclerosis. Acta Neurol Scand 2000;101:85-8.

12. Weinshenker, B. Epidemiology of multiple sclerosis. Neurol Clin 1996;14:291-308.

13. Mayer S, Hillis LD. Prinzmetal's variant angina. Clin Cardiol 1998;21:243-6. 